\title{
The Impact of Computerization on Library Support Staff: A Study of Support Staff in Academic Libraries in Wisconsin
}

\author{
Cathleen C. Palmini
}

\begin{abstract}
This 1992 survey explores the effects that computerization of libraries has had on the work and job satisfaction of over 200 support staff employed in academic libraries in Wisconsin. Among the questions addressed are period and area of employment, type of automated systems used, percentage of time spent at computer terminals, adequacy of training, change in overall effectiveness since computerization, and change in job satisfaction. Responses to open-ended questions reveal that many support staff are concerned not only with the specifics of their jobs but also with larger questions facing academic libraries.
\end{abstract}

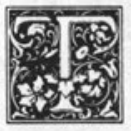

he computerization of libraries has changed and continues to change the positions of academic library support staff. A growing body of literature addresses other library support staff issues. In "The Role, Status, and Working Conditions of Paraprofessionals," Larry R. Oberg et al. provide an excellent review of the literature on support staff as well as information on paraprofessionals in academic libraries based on administrators' responses to a nationwide survey." In "Job Satisfaction among Support Staff in Twelve Ohio Academic Libraries," Coleen Parmer and Dennis East explore support staff satisfaction in five job dimensions (supervision, coworkers, work, benefits, and pay), but they do not isolate computerization as a factor in job satisfaction. ${ }^{2}$ In 1987 Dorothy E. Jones surveyed support staff in three academic libraries to determine their attitudes toward technology in what she terms the "the technology-acquisition period." ${ }^{\prime 3}$ The impact of computerization on support staff, both in the work they do and in their attitudes toward their jobs, has not been explored across a large number of academic libraries or since the use of computers in libraries has become widespread.

The purpose of this survey was to explore the effect computerization has had on Wisconsin academic library support staff. ${ }^{4}$ The resulting objective data are reported. In addition, a sample of the statements written by support staff in response to the questionnaire is quoted. This approach provides the reader not only with the percentage response to questions but also with an indication of the outpouring of comments written by support staff. From these written comments, the picture of support staff which emerges is that of a vital and vocal group of individuals who wish to express themselves and to be heard on issues relating to the computerization of libraries.

Cathleen C. Palmini is a Library Services Assistant II, Government Publications Department, University of Wisconsin-Stevens Point, Stevens Point, Wisconsin 54481. 


\section{SURVEY METHODOLOGY}

This survey was supported by the University of Wisconsin-Stevens Point and the Support Staff Roundtable of the Wisconsin Library Association. The sixteen-question survey instrument was developed to elicit information from Wisconsin academic library support staff on their library background, working conditions (especially with regard to computer use), attitudes toward the computerization of their positions, and causes of job satisfactions and frustrations. In addition to objective responses, eight questions allowed for written comments from the respondents and the final three questions were open-ended. Librarians and support staff at the University of WisconsinStevens Point reviewed the questionnaire and support staff at four academic libraries pretested the questionnaire.

The picture of support staff which emerges is that of a vital and vocal group of individuals who wish to express themselves and to be heard on issues relating to the computerization of libraries.

Since no statewide directory of support staff existed, contact people in each of the University of Wisconsin System Libraries (with the exception of University of Wisconsin-Madison) distributed the questionnaire in January and February of 1992. These contact people on campuses statewide were support staff known by the author or officers of the Wisconsin Library Association Support Staff Roundtable. Contact people agreed to distribute the questionnaires to mailboxes of support staff, refer questions back to the author, have questionnaires returned to their mailboxes, and mail questionnaires back by a specified date. University of Wisconsin campuses at Eau Claire, Green Bay, La Crosse, Milwaukee, Oshkosh, Parkside, Platteville, River Falls, Stevens Point, Stout, Superior, and Whitewater were involved in this method of distribution.
Because of its widespread system of general and specialized academic libraries, questionnaires were sent in February 1992 to the University of Wisconsin campus using personnel lists through campus mail. The questionnaires were returned to a library contact person.

In addition, a small sample of support staff employed at private academic libraries was obtained by distributing questionnaires at the April 1992 statewide Support Staff Conference in Madison, Wisconsin.

The overall response rate from the approximately 400 support staff employed at University of Wisconsin system libraries was 50 percent. The response rate from the two largest University of Wisconsin campuses, University of Wisconsin-Madison and University of Wisconsin-Milwaukee, was 30 percent. The relatively large size of their library systems and the lack of personal acquaintance of respondents with the contact person may account partially for the response rate. The response rate from the other twelve University of Wisconsin system campuses (listed above) was 80 percent.

\section{SURVEY RESULTS}

\section{Length of Employment}

When asked about longevity on the job, library support staff in Wisconsin proved to be a stable group. Sixty percent reported working in a support staff position in a library for over ten years, and nearly one-third of the total group has been employed in a support staff position for over fifteen years (see table 1).

One might suspect that such longterm employees would have difficulties adapting to the new procedures brought on by computerization or express less

TABLE 1

YEARS EMPLOYED IN A LIBRARY SUPPORT STAFF POSITION

\begin{tabular}{cc}
\hline Years Employed & \% of Support Staff \\
\hline $1-5$ & 22 \\
$11-15$ & 18 \\
$16-20$ & 15 \\
$20+$ & 17 \\
\hline
\end{tabular}


job satisfaction. However, in response to other questions, most support staff did not report this to be the case.

\section{Area of Employment in the Library}

When asked of what their work consisted, the largest percentages of respondents reported working primarily in Circulation (24 percent) or Cataloging (21 percent). The next largest areas of employment were Serials and Acquisitions, each at 11 percent. If support staff worked in more than one area (and over one-third did), they were asked to indicate the percentage of time worked in each area. For the numbers in table 2, support staff were counted in the area in which they worked the most.

For example, only 5 percent of support staff reported working primarily in Reference, but another 14 percent worked in Reference as a secondary part of their job. Several of the support staff working in a combination of areas mentioned the difficulty of mastering computer applications in more than one area. One respondent commented: "Because of the variety of computers I work on in a day, there are times I sit down at a screen at the end of the day and draw a blank as to what protocol, codes, passwords and system I'm on."

\section{Years of Library Automation}

Most support staff are no longer newcomers to using computerized sys-

\section{TABLE 2}

PRIMARY AREA OF

EMPLOYMENT IN THE LIBRARY

\begin{tabular}{lc}
\hline Area Employed & \% of Support Staff \\
\hline Circulation & 24 \\
Cataloging & 21 \\
Serials & 11 \\
Aquisitions & 11 \\
Other & 11 \\
Administrative area & 9 \\
Interlibrary loan & 5 \\
Reference & 5 \\
Government documents & 3 \\
Reserve & 1 \\
\hline
\end{tabular}

$37 \%$ worked in a combination of areas. tems in libraries. At the time of the survey, 89 percent of support staff reported their library had been using computerized systems for three years or longer. Only 11 percent reported that their library had been using computers less than three years. These support staff worked in private academic libraries or small, specialized libraries in the University of Wisconsin-Madison library system.

\section{Support Staff Use of Automated Systems}

When asked which automated systems were used on their job, 75 percent of respondents reported using an online catalog regularly. Those support staff employed by the University of WisconsinMadison or Milwaukee used the NLS system (as the online catalog is known), while other University of Wisconsin system libraries used the LS2000 online catalog system at the time of the survey.

"Because of the variety of computers I work on in a day, there are times I sit down at a screen at the end of the day and draw a blank as to what protocol, codes, passwords and system I'm on."

Nearly two-thirds of support staff used word processing programs and two-thirds also made regular use of email. Nearly half did cataloging/searching on OCLC. Nearly half also used an automated circulation system. Automated cataloging systems, such as NOTIS or LS2000, were used by 37 percent of support staff. Use of CD-ROM databases was reported by 22 percent of support staff and use of automated acquisitons systems was also made by 22 percent (see table 3).

\section{Hours of Work at Computer Terminals}

Widespread use of such systems means hours spent working at computer terminals for support staff. Half of support staff spend more than 50 percent of their working day at a terminal. Twenty percent of total support staff work over 75 percent of their time at a computer (see table 4). 
TABLE 3

AUTOMATED SYSTEMS USED ON THE JOB

\begin{tabular}{lc}
\hline Automated System & $\begin{array}{c}\text { \% of } \\
\text { Support } \\
\text { Staff }\end{array}$ \\
\hline Online catalog & 75 \\
E-mail & 66 \\
Word processing & 63 \\
Circulation system & 46 \\
OCLC & 46 \\
Cataloging system & 37 \\
Other (spreadsheet, data- & 31 \\
$\quad$ manager, graphics, etc.) & \\
CD-ROM databases & 22 \\
Acquisition system & 22 \\
Serials system & 13 \\
Interlibrary loan system & 13 \\
\hline
\end{tabular}

TABLE 4

TIME SPENT AT A COMPUTER TERMINAL

\begin{tabular}{cc}
\hline \% of Time at Terminal & \% of Support Staff \\
\hline $0-25$ & 19 \\
$26-50$ & 31 \\
$51-75$ & 30 \\
$76-100$ & 20 \\
\hline
\end{tabular}

Such long hours at computers led some respondents to comment about health problems related to computer use, including eyestrain and the problems caused by repetitive motions. Some support staff believed that their management showed indifference to the working conditions that cause computer-related health problems.

Other comments indicated that support staff were not unhappy with computers, but with the amount of time they were expected to work at computers. One wrote: "I'll admit, my first reaction to inputting on a computer is 'this is fun.' But eight hours a day? Not good for anyone."

\section{Training for Computer Use}

In responding to a question on training for computer use, 62 percent believed that training was adequate and
38 percent found training inadequate for the use they made of computers. Since over one-third of support staff said they were inadequately trained for computer use, this response indicates a problem area for academic libraries.

\section{Some support staff believed that their management showed indifference to the working conditions that cause computer-related health problems.}

While some support staff stated they enjoyed the challenge of learning on their own computer applications necessary for their job, more said they felt dissatisfied with having to learn on their own and cited poorly written manuals as part of the problem. In both cases many voiced frustration with the lack of time to learn new systems.

\section{Computer Background in Hiring}

Will some computer background be necessary for future applicants for support staff positions? Of the 47 percent responding yes, one person stated: "Library schools should emphasize that if you don't like computers, stay out of the library field!" Only 13 percent responded that no computer background would be necessary, and 41 percent checked the answer "possibly" computer background would be necessary. Most of these support staff were trained on the job themselves because they were hired before the computerization of their libraries. Several felt as this respondent did: "I think it is necessary for applicants to be willing to learn, not necessarily have specific knowledge. There are so many programs, etc. that knowledge of one does not mean you will know all others-it will make you more comfortable learning new systems, however."

Computer background for student assistants was not addressed on the questionnaire but was an issue brought up by support staff answering the questionnaire. In addition to training new student assistants in the usual tasks, support staff now must train them also 
on one or more computer systems. The staff of one Acquisitions Department believed that students stayed with them too short a time to make it effective to train students in computer functions.

\section{Effect on Job Satisfaction}

Over half of support staff reported feeling more job satisfaction since the computerization of their libraries. They cited such factors as the opportunity to learn new skills, better ways to find things for patrons, and the streamlining of procedures.

Thirty-two percent felt about the same job satisfaction before and after computerization. Many explained that they felt about the same because new satisfactions and new frustrations balanced out, as this respondent expressed: "I feel very satisfied when I accomplish a major task on the computer. I also feel very frustrated when things don't work right-especially after several attempts."

Only 13 percent of support staff reported feeling less job satisfaction since computerization. While this was a small group, they voiced strong feelings in their written comments. One commented: "Before computerization, I felt like my workload was reasonable and procedures were relatively stable. Since computerization, the workload is impossible and because of the ever-changing procedures, staff have trouble digesting everything, resulting in inconsistent work and frustration."

\section{Computers as Timesaving}

In the opinion of many, computerization of support staff's work load has not been a big timesaver. When asked about the portion of their job which was computerized, only 39 percent reported it had become less time-consuming, while 36 percent reported that it was more time-consuming and 26 percent said it had remained about the same.

One group of support staff, catalogers, mentioned having to perform too many steps to complete a single task and said that they found some procedures laborious on the computer. Another group working in serials areas noted that working on serials with their title changes and frequency changes did not adapt efficiently to computerized systems. Support staff from other areas responded more positively to the timesaving aspects of computers. In circulation, a support staff member emphasized the freedom of letting the machine generate overdues and statistics.

\section{Over half of support staff reported feeling more job satisfaction since the computerization of their libraries.}

Support staff pointed to poorly designed systems as being part of the problem of the lack of efficiency of computer use. One respondent, after first identifying herself as a computer enthusiast, stated: "I'm very frustrated by what libraries put up with in poor quality systems for the tremendous expense." Also mentioned were software changes that made procedures different, but not better as promised: "It seems obvious that users are not consulted in software updates." Another support staff member stated: "Some things are facilitated but there is a lot more equipment to troubleshoot and explain. There should be standards in writing software so that a person needn't have to remember five or six ways to do the same operation depending on the system."

\section{Effectiveness}

In a related question, support staff were asked: "Has automation increased your overall effectiveness on the job? (Are you getting more done?)." Of those responding, 64 percent said yes to an increase in overall effectiveness, 18 percent no, and 18 percent about the same. These results seem somewhat contradictory to the results of the previous question, but comments written by respondents indicated that this question was often interpreted in a larger sense of what computerization means to the overall functioning of the library. Thus, many support staff felt that because of automation, they were providing better 
overall service or providing better cataloging records or making the library easier to use for patrons.

When responding to this question, some support staff pointed out that increased efficiency should not be viewed alone. In Interlibrary Loan, one respondent wrote that yes, she was getting more done but the volume had increased almost 600 percent since automation. Another staff member was unsure whether she was getting more done: "There seems to be more I should have done than ever. Maybe the expectations have increased faster than my ability to complete them." Comments of several support staff echoed this statement: "I'm getting more done, but working much harder. Stress levels are much higher."

\section{Causes of Job Frustration}

One of the open-ended questions asked: "What part of your job causes you the most frustration?" Note that this question did not indicate that the frustrations were to be solely computer-oriented. Similar written-in responses were grouped in categories. Percentages were calculated using those similar responses appearing five or more times (see table 5).

Computer-related frustrations totalled 62 percent of all responses. The biggest single source of job frustration was when the computer was down ( 26 percent of all responses). Because of the extensive use of computers by support staff, this means that staff will experience interrupted workflow or perhaps accomplish nothing until the computer is functioning again. Other respondents mentioned the lack of computer support or repair staff as a major frustration.

The computer being down creates even more stress among the many support staff who felt there was not enough time to do their job. The second-largest group of responses (21 percent) mentioned that the workload was too great, that their libraries were understaffed, and that they did not have enough time to complete their work. While most respondents did not indicate whether this lack of time was primarily computer-related, some mentioned the lack of time to learn new systems.

Other respondents indicated frustration with computer problems: slow response time of computers ( 9 percent), not enough terminals ( 7 percent), too many different systems to learn (6 percent), not enough training (5 percent), health problems related to computers ( 5 percent), and too much time on computers ( 3 percent). It should be remembered

\section{TABLE 5 \\ PRIMARY CAUSE OF JOB FRUSTRATION \\ (ONE RESPONSE PER SUPPORT STAFF)}

\begin{tabular}{ll}
\hline $\begin{array}{l}\text { \% of Support } \\
\text { Staff Responding }\end{array}$ & \multicolumn{1}{c}{ Cause of Frustration } \\
\hline 26 & The computer is down. \\
21 & Work load, being understaffed, lack of time. \\
9 & Slow response time on computers. \\
7 & Not enough terminals. \\
7 & People, problem personalities. \\
7 & Management/librarians and their attitude toward support staff. \\
6 & Too many different systems to learn. \\
5 & Not enough training (38\% of total respondents on the adequacy training \\
5 & question). \\
4 & Health problems related to computer use. \\
3 & Computers, too much time on computers. \\
\hline
\end{tabular}


that this was an open-ended question asking for one response (what part of the job causes the most frustration). It did not provide respondents with a list to check several causes of frustration.

Comments of several support staff echoed this statement: "I'm getting more done, but working much harder. Stress levels are much higher."

The remaining 17 percent of respondents mentioned people-oriented frustrations (counting lack of time responses as neither computer- nor people-oriented), such as coping with problem patrons ( 7 percent) and other staff ( 3 percent). Another group of respondents cited the main source of frustration as administrators (or librarians) and their attitudes toward support staff ( 7 percent).

One Circulation support staff member's frustration was: "unhappy patronswhether with the computer system, our library policies - or whatever they decide to take out on the staff at the desk." One cataloger mentioned: "Cataloging positions now leave little contact with other patrons/staff. We're glued to a terminal whereas with the card catalog, we knew there was life through the cataloging doors." Several support staff mentioned stress levels on the job: "Life is more stressful because of the tremendous quantity of details which now must be addressed, plus there is a constant pressure to upgrade technical knowledgealways adding more and more to do."

\section{Sources of Job Satisfaction}

The question on job satisfaction was similarly open-ended: "What part of your job gives you the most job satisfaction?" Responses were tallied using the same method as the question above (see table 6).

A total of 60 percent of the responses on the primary source of job satisfaction were people-oriented. Of these responses, the largest number ( 43 percent of the total) came from support staff who indicated that their greatest job satisfaction came from dealing with patrons or working with people. Other peopleoriented satisfactions came from working with other staff members (10 percent) and supervising students (7 percent). One support staff member wrote her greatest satisfaction "continues to be the patrons who express satisfaction or appreciation for 'a great service.'”

Computers as a primary source of satisfaction were cited in 11 percent of the responses (accuracy and speed of computers, liking computers, job more interesting since computers). Finding satisfaction in computer use, one support staff member stated that computerization "has offered new challenges and opportunity for personal growth, making my position more stimulating." Another wrote: "I enjoy the challenge and

\section{TABLE 6}

PRIMARY CAUSE OF JOB SATISFACTION (ONE RESPONSE PER SUPPORT STAFF)

$\%$ of Support
Staff Responding

43

18

11

10

7

5

4
Cause of Satisfaction

Helping patrons, working with people, being thanked.

Getting the work done, doing a good job, completing a challenge.

Accuracy and speed of computers, like computers, job now more interesting.

Other staff.

Supervising students.

Diversity of the job.

Working in cataloging, making materials more easily accessible. 
excitement of using computer products and services."

Other responses may be based on satisfactions related to computer use but were not clearly stated by support staff as such: getting the job done or doing a good job (18 percent), the diversity of the job (5 percent), cataloging work or making materials more easily accessible for patrons ( 4 percent). "Seeing an empty cart after it was full!" was how one respondent expressed herself.

\section{Additional Comments on Computerization}

The final question asked for additional comments on how computerization has affected the support staff member's position. Most support staff wrote a response to this and other openended questions. The comments here ranged from some very positive comments about computerization to a few very negative. Many support staff wrote at length and many thoughtfully considered both what has been gained with computerization and what problems it has caused. A sample of the written responses follow.

"Computerization has been an interesting and stimulating addition to my job. The only frustration has been that there often is not time to 'play around' and learn new applications and systems."

"Overall, I believe that computerization has increased the workload of my job. In some instances it has made tedious tasks much less time-consuming and deadening; but in other respects, there is greater pressure to use all the latest technological advances and there does not seem to be adequate time to familiarize oneself with all the programs one needs to know."

"I've found that patrons seem to expect the sky now.... These expectations, not based on what can realistically be provided, can cause a lot of stress at a public service point."

"Library administration is not fully tuned in to the time demands of the procedures expected."

"I used to be a cataloger on OCLC and disliked all the time I had to spend in front of a VDT screen; since moving to Reference, all is different. I'm checking into many different databases searching for the right one for each question and I feel I'm using it, rather than being used by the machine."

"As far as I'm concerned, either you roll with the punches or you get left behind, and it can be great fun!"

"There are days you can't live with it [computerization], but most days you don't want to live without it either."

\section{For those support staff spending large amounts of time working on terminals, the need is expressed to spend less time in that area, to have more people contacts or more variety in the work involved in their positions.}

"It's important to remain flexible and open to change. My position will probably change as much in the next ten years as it has in the previous ten. These are exciting times in the information field and I look forward to the innovations which are sure to come."

\section{CONCLUSION}

The comments of three support staff respondents help to summarize the findings of this survey.

"Although learning the new methods has been challenging, the old methods were more peaceful." In recent years, most support staff have moved from the comfortable into the unknown. Learning the new methods and ongoing work with computers have been stressful for many support staff. Changes suggested by the respondents of this survey would help alleviate part of this stress. More adequate training on computers is considered essential by many support staff. The need for administrators to recognize and take action to eliminate computerrelated health problems (such as better designed workstations) is cited by some support staff. For those support staff spending large amounts of time working on terminals, the need is expressed to spend less time in that area, to have more 
people contacts or more variety in the work involved in their positions. Support staff see themselves as good sources of information on the better design of systems on which they spend long hours.

"Things seem to be happening almost faster than even reasonably extraordinary people can keep up with them." Support staff have been "reasonably extraordinary" in adapting to the computerization of their positions. Most have been successful in adapting to radically different procedures in a relatively short period of time. Despite computeroriented frustrations, most support staff feel that overall their effectiveness has improved and that their job satisfaction has improved or not been affected. An often-expressed feeling was that there is not enough time to keep up, either with the present work load or with the changing technology.

"Access to information is so much greater now and users appreciate the power and relative ease of use." This writer helps to put the use of computers by support staff into perspective. In libraries, support staff aid in the process of getting information to the library user, and most support staff find their greatest satisfaction in working with these library users as well as working with other staff members. While support staff are frustrated with computers when they are down, are poorly designed, or have other problems that interfere with completing work, staff laud computerization of libraries as an improvement in providing this access to information.

\section{REFERENCES AND NOTES}

1. Larry R. Oberg, Mark E. Mentges, P. N. McDermott, and Vitoon Harusadangkul, "The Role, Status, and Working Conditions of Paraprofessionals," College \& Research Libraries 53 (May 1992): 215-38.

2. Coleen Parmer and Dennis East, "Job Satisfaction among Support Staff in Twelve Ohio Academic Libraries," College \& Research Libraries 54 (Jan. 1993): 43-57.

3. Dorothy E. Jones, "Library Support Staff and Technology: Perceptions and Opinions,"

Library Trends 37 (Spring 1989): 432-56.

4. The term support staff will be used throughout this article. It was adopted by the Wisconsin Library Association Support Staff Roundtable and is interchangeable with the term paraprofessional as defined and used in Oberg's article.

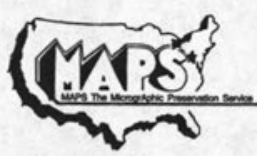

MAPS is now Preservation Resources. Our name change reflects the evolution of our organization and reiterates our ongoing commitment to provide the library and archive community with the highest quality preservation microfilming and other related services.

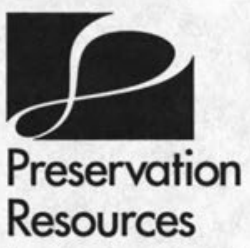

Nine S. Commerce Way Bethlehem, Po 18017-8916 1-800-773-7222

A division of OCLC Online Computer Librory Center, Inc. 


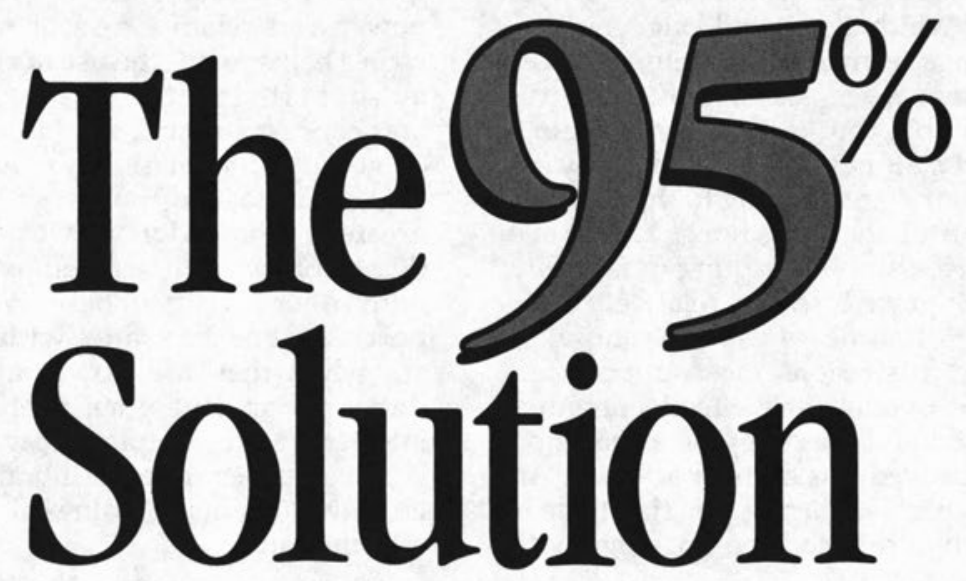

You get one chance with authority control, so it's important to get it done right. LTI guarantees that its affordable, machine-only authority control will link $95 \%$ or more of your library's controlled headings to an LC or LTI authority record. No exceptions! No excuses!

When manual review is requested, only professional librarians are used as editors and link rates approach $100 \%$.

LTI maintains the complete LC MARC authority files (updated weekly), supplemented with over 410,000 LTI authority records and 350,000 proprietary "cross links."

Contact LTI for more information on authority record link results.

"Authority Control for the 21st Century"

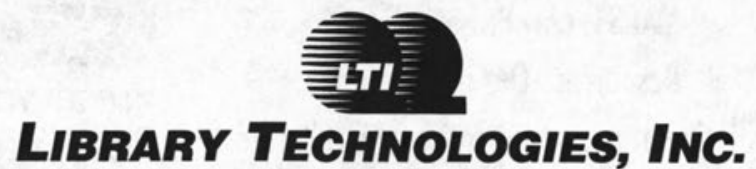

1142E Bradfield Road Abington, PA 19001

(215) 576-6983 Fax: (215) 576-0137

(800) 795-9504 